\title{
Study on the Performance Optimization of Knitted Fabric Anti-Roll by Tissue Structure
}

\author{
Guoqiang Chen ${ }^{*}$, Yanan Zhu ${ }^{2}$ \\ ${ }^{1}$ Jiangxi Center for Modern Apparel Engineering and Technology, Jiangxi Institute of Fashion Technology, \\ Nanchang, China \\ ${ }^{2}$ School of Textile and Clothing, Jiangnan University, Wuxi, China \\ Email: *ch-guoqiang@163.com, b342834547@qq.com
}

How to cite this paper: Chen, G.Q. and Zhu, Y.N. (2018) Study on the Performance Optimization of Knitted Fabric Anti-Roll by Tissue Structure. Journal of Materials Science and Chemical Engineering, 6, 1-5. https://doi.org/10.4236/msce.2018.64001

Received: October 12, 2017

Accepted: April 5, 2018

Published: April 12, 2018

\begin{abstract}
Will use the same number of positive and negative coil longitudinal organization of fabric is ta edge sex used in the work of the organization to warp fabric edge sex, between restrained knitting principle, design a kind of weft basketwork weaving method, especially in weft knitting machine woven from has the edge of weft knitted fabric performance weaving method. In order to overcome the existing technology aims to make weft basketwork structure of a single organization, edge sex is bad, or can't produce rich weft knitted fabric appearance of shortage, provide a resistance to edge weft knitted fabric weaving method.
\end{abstract}

\section{Keywords}

Organizational Structure, Knitted Fabric, Resistance to Edge, Performance Optimization

\section{Introduction}

In the free state of the knitted fabric, due to the disappearance of the inner stress of the edge coil of the fabric, the natural wrapping phenomenon of the marginal fabric is caused, namely, curling. The crimping of knitted fabric is mainly influenced by the structure of fabric, length of yarn, fineness, elasticity and density. Among them, weft knitted fabric and double-reverse knitting structure, will produce different degrees of crimping effect [1]. Edge sex is usually defined as one of the drawbacks of weft knitted fabric, it is easy to cause garment seams edge size change or pieces of uneven phenomenon, ultimately affect the garment size specifications and clothing ensemble effect, in particular, weft plain fabric such as individual organizational structure of the fabric [2]. 
At present, the method of improving the margin of weft knitting fabric has been known, mainly through the processing technique of the finish of the fabric and the improvement of the structure of the cloth side. For example: in the design of the sample, the arm is handled by adding the component size; At the edge of the fabric, it is inserted into the rib structure or the rolling process, and the method of inlaying the lining of the edge of the garment to relieve the edge of the roll. However, this results in the complexity of the fabric making process and the increasing operation cost, which fails to solve the problem of the fabric's edge [3]. In addition, based on the traditional fabric organization design scheme and the influence of the operation of equipment and equipment at that time, most of the fabrics produced in the fabric are more unitization and lack of new ideas. It can't be produced on an organizational structure, especially in the structure of individual organizations such as the weft needle, etc., and the textile products have the anti-roll edge, and the hand feel is plump and beautiful in appearance. In this paper, the weaving method of knitted fabric with anti-curling weft knitting is studied, especially the weaving method of weft knitting knitted fabric with anti-curling properties woven by weft knitting machine.

\section{Principles and Experiments}

\subsection{Weaving Principle}

Weft needle tissue is a single weft knitted fabric with continuous coil sequence, which has the characteristics of the coil tilting, the edge of the coil, the lengthwise and the transverse. Rib or double-sided fabrics, because of the transverse or longitudinal array coil, its corresponding yarn section bending direction is the opposite condition, and appear in different plane, the subsidence of arc by the former to the later, again by the first of the coil of the front side of the connection each other, in the opposite direction of the elastic restoring force, under the action of the fabric edge is not obvious. Rib group is made up of positive wale wale and opposite, and according to certain combination configuration, and has great flexibility, the same amount of positive and negative in the wale rib in the organization, due to the force balance each other cause edge, and therefore does not appear edge phenomenon, For example $1+1,2+2$ or $5+3$ Rib etc [4]. For example: $2+2$ rib group, is composed of both the front and wale in the form of $2: 2$ and combination, the configuration of double weft knitted fabric, the structure features are: horizontal has great flexibility and good extensibility. In the same rib organization, the transverse unrolled edge. In the different rib tissues of the positive and negative coils, the edge phenomenon is not serious [5].

Will use the same amount of positive and negative $1+1$ and wale rib organization without edge of the fabric used in work organization of fabric edge sex, both the weaving principle of mutual restraint, the flat organization and two kinds of yarn rib organization trap woven fabric, which can effectively control the weft knitted fabric edge coefficient. 


\subsection{Experimental}

Based on the combination of weft tissue and rib organization, the principle of the anti-roll edge of fabric is realized, and a knitted fabric of knitted fabric is designed, as shown in Figure 1. In this case, $1+1$ rib structure is adopted; The computer horizontal machine system adopts the machine equipment developed by the changshu golden dragon computer, which is LXC-121SC. The needle selection is $7 \mathrm{G}$.

In the process of concrete operation, the yarn used in the operation of the yarn needs to be processed as follows: raw material selection, raw material test, tube, staining, shaping, weaving [6]. In this case, the selected yarn components are: $100 \mathrm{C}$, yarn count: $4.5 \mathrm{Nm} / 2$. In addition to the pretreatment of yarn, the following steps are included:

1) design of fabric texture, refers to the design of according to different needs, market demand and the current knowledge of weaving technology operation, and can design expression of color, texture, shape and level of fabric texture design.

2) the organization of the fabric design, including the following two processes: first, the organization of the weft plain fabric design: to the organizational structure of laying series, using the computer aided design control to make the corresponding positive weft plain fabric grain version of the file.

The interweaving and interweaving rules of the knitting yarn are controlled by the structure of positive weft needle series, so as to control the texture effect, color and level of the front fabric. The reverse rib structure controls the interweaving and interweaving of the rib fabric, so as to control the texture effect, color and level of the reverse fabric.

3) by using the computer aided design software system, the paper of the front and back fabric is synthesized to obtain the texture of the fabric [7].

4) the fabric grain version of the file input computer flat knitting machine, refer to Figure 1, an edge fabric weave diagram, use needle bed moving, adjust the subsidence of arc, yarn tension state and organized into a circle, weaving the edge knitted fabric. See Figure 2.

\section{Results and Discussions}

Weaving method introduced in this paper, the product of the final appearance break the routine, the innovation and form the edge resistance good, feel is plump, has a unique appearance of weft knitted fabric art effect. Using different conventional organization principle analysis, improve the weaving method, through the change of the organization, fabric to smooth, smooth natural cohesion, fabric appearance and lively fashion, colorful, rich individual character, more weft knitted fabric with unique appearance, artistic effect; Through the weaving weaving method of knitted fabric has good scalability, flexibility, and warm air permeability, feel plump, fabric garment body deformation is poor, close-fitting sex good, wearing comfortable, soft without constriction [8]. 
(2)

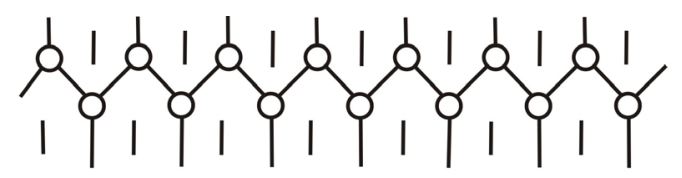

(1)

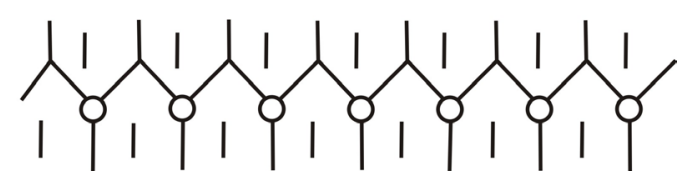

Figure 1. Weaving diagram.

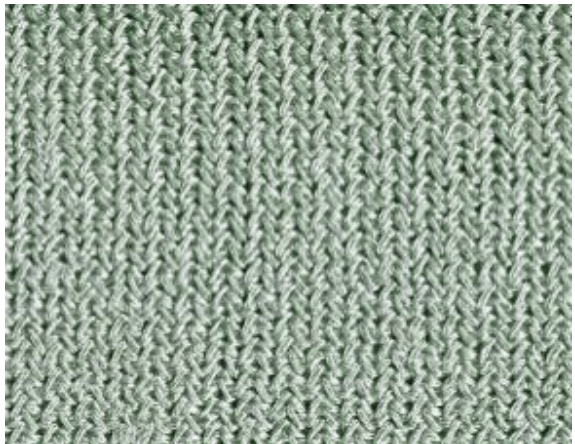

(a)

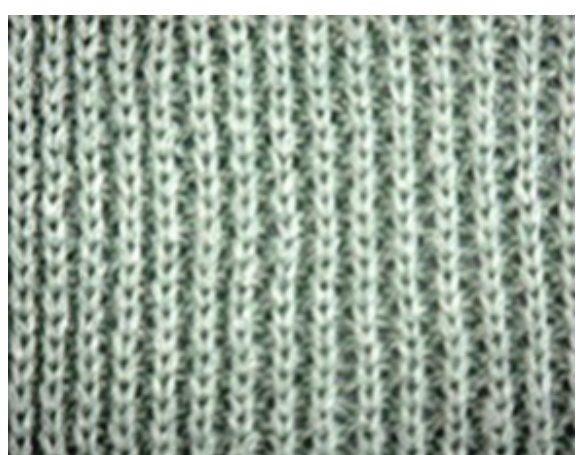

(b)

Figure 2. Physical effect drawing. (a) Front face; (b) Reverse side.

This weaving method, its yarn characteristic can be natural fiber, synthetic fiber or man-made fiber. The structure of its fabric is characterized by a circular knitting structure, which is a combination of weft and rib tissues. When laying the structure of the fabric series, the yarn arrangement can be the same or different. It is important to note that in the organization design of the steps, the structure of the fabric must be corresponding when the series structure of the fabric is laid. In addition, the specification of yarn raw materials used for the production of anti-rolled edge knitted fabric can be the same and different.

\section{Conclusions}

This article describe the edge of the weft knitted fabric weaving method, except in the early period of the yarn processing, also includes the following steps: the fabric texture design, organization design, fabric grain synthetic version of the file, the final fabric print version of the file input computer flat knitting machine, then use needle bed moving, adjust the subsidence of arc, yarn tension state and organized into a circle, produce an edge knitted. The beneficial effects of this weaving method is: forming edge resistance, good fabric to smooth, smooth natural cohesion, fabric appearance and lively fashion, colorful, rich individual character, more weft knitted fabric with unique appearance, artistic effect; The weaving method weaving fabric has good scalability, flexibility, and warm air permeability, feel plump, fabric garment body deformation is poor, close-fitting sex good, wearing comfortable, soft without constriction. 
Hope in this paper, the resistance of the edge of the weft knitted fabric weaving method, can be used for fabric production and application in clothing enterprises, and expect to production of knitted fabric and its organizational structure design has certain help.

\section{References}

[1] Hung, O.N., Chan, C.K., Kan, C.W. and Yuen, C.W.M. (2017) Effect of the $\mathrm{CO}_{2} \mathrm{La}-$ ser Treatment on Properties of 100\% Cotton Knitted Fabrics. Cellulose, 24, 1915-1926. https://doi.org/10.1007/s10570-017-1224-y

[2] Lizák, P., Legerská, J. and Mojumdar, S.C. (2013) Influence of Knitted Structures on Heat Transfer. Journal of Thermal Analysis and Calorimetry, 112, 1089-1094. https://doi.org/10.1007/s10973-013-3104-5

[3] Richard, S.W., Benjamin, L. and Nicholas, H. (2007) OpenGL Super Bible. 4th Edition, Addison Wesley, New Jersey, 173-228.

[4] Göktepe, Ö. and Harlock, S.C. (2002) Three Dimensional Computer Modelling of Warp Knitter Structures. Textile Research Journal, 72, 266-272. https://doi.org/10.1177/004051750207200314

[5] Aggie, C. (2007) Shape Memory Behavior of SMPU Knitted Fabric. Journal of Zhejiang University (Science A: An International Applied Physics \& Engineering Journa), 5, 830-834.

[6] Dias, T. and Delkumburewatte, G.B. (2008) Changing Porosity of Knitted Structures by Changing Tightness. Fibers and Polymers, 9, 76-79. https://doi.org/10.1007/s12221-008-0012-6

[7] Varnaitė-Žuravliova, S., Stygienè, L., Krauledas, S., Minkuvienè, G., Sankauskaitè, A. and Abraitienè, A. (2015) The Dependance of Effectiveness of Incorporated Microencapsulated Phase Change Materials on Different Structures of Knitted Fabrics. Fibers and Polymers, 16, 1125-1133. https://doi.org/10.1007/s12221-015-1125-3

[8] Herath, C.N. (2013) Investigation of Air Permeability of Core Spun Cotton/Spandex Weft Knitted Structures under Relaxation. Fibers and Polymers, 14, 1339-1346. https://doi.org/10.1007/s12221-013-1339-1 